\title{
A Comprehensive Overview of Hybrid Electric Vehicles
}

\author{
Caiying Shen, ${ }^{1}$ Peng Shan, ${ }^{1}$ and Tao Gao ${ }^{2,3,4}$ \\ ${ }^{1}$ College of Automobile and Transportation, Liaoning University of Technology, Liaoning, Jinzhou 121001, China \\ ${ }^{2}$ Electronic Information Products Supervision and Inspection Institute of Hebei Province, Hebei, Shijiazhuang 050071, China \\ ${ }^{3}$ Industry and Information Technology Department of Hebei Province, Hebei, Shijiazhuang 050051, China \\ ${ }^{4}$ School of Electrical Engineering and Automation, Tianjin University, Tianjin 300072, China
}

Correspondence should be addressed to Tao Gao, gaotao@ieee.org

Received 3 March 2011; Revised 21 June 2011; Accepted 11 September 2011

Academic Editor: Rakesh Mishra

Copyright ( 2011 Caiying Shen et al. This is an open access article distributed under the Creative Commons Attribution License, which permits unrestricted use, distribution, and reproduction in any medium, provided the original work is properly cited.

As the environmental pollution and energy crises are getting more and more remarkable, hybrid electric vehicles (HEVs) have taken on an accelerated pace in the world. A comprehensive overview of HEVs is presented in this paper, with the emphasis on configurations, main issues, and energy management strategies. Conclusions are discussed finally.

\section{Introduction}

In 1834 , the first vehicle, actually a tricycle, powered by battery, was developed. But with the improvement in the internal combustion engine (ICE), ICE vehicles (conventional vehicles) have occupied an absolute share in the market; pure electric vehicles (PEVs) have almost disappeared since 1930's. First, let us investigate the global growth of population and vehicles in the next 50 years [1]. We can see from Figure 1 that the global population will increase from 6 billion in 2000 to 10 billion in 2050, and Figure 2 illustrates the global vehicles will increase from 700 million to 2.5 billion consequently. If all vehicles are powered by internal combustion engines, the gasoline and diesel oil will be depleted quickly, and the emission will result in green house effect. So, the energy conservation and environmental protection are growing concerns around the world.

It is reported that vehicles emission accounts for $39.2 \%$ of the total emission in 2007 [2]; there must be a drastic reduction in emission if humans want to avoid catastrophic greenhouse effect, thus the governments all over the world adapt strict emission regulations, for example, Emission Standard of Automobile of Europe IV Standard has been put in practice in Europe since 2005 [3]. Meanwhile, fuel duty taxes were imposed by government; higher crude oil price plus fuel duty taxes result in higher fuel prices. So, Automobile
Company sis forced to develop EV for low-emission and high-fuel economy under laws and market together.

$\mathrm{EV}$ is a road vehicle which involves with electric propulsion [4-6]. EV can be classified into three types: pure electric vehicles (PEVs), hybrid electric vehicles (HEVs), and fuel cell electric vehicles (FCEVs). Today, they are in different stages of development due to existing technology, the major characteristics and features of three types of EV as shown in Table 1. We can see that electric motor drives technique, in which the field-oriented control (FOC) and variable-voltage variable frequency (VVVF) are adapted widely, is the common technique in EV. The battery initial cost and battery management create bottleneck in PEVs in spite of zero emission; these two barriers cannot be solved in the near future, so the HEV is the interim solution before the full commercialization of PEV when there is a breakthrough in battery initial cost and management. FCEV has long-term potential for future main stream vehicles [7-10], however the technology of its cost and refueling system is still in early development stage [4], thus this paper mainly discusses HEV. Different from other papers, control principles of HEV is explained in detail in this paper. This paper is organized as follows. Section 1 is the introduction. Configurations and main issues of HEV are described in Section 2 with emphasis on the energy management (EM). Finally, the main points and significant results of this paper are summarized in conclusions. 
TABLE 1: The major characteristics and features of three types of EV.

\begin{tabular}{|c|c|c|c|}
\hline Types of EV & PEV & $\mathrm{HEV}$ & FCEV \\
\hline Energy source & (i) Battery & $\begin{array}{l}\text { (i) Battery/ultracapacitor } \\
\text { (ii) Internal combustion engines }\end{array}$ & (i) Fuel cells \\
\hline Propulsion technique & (i) Electric motor drives & $\begin{array}{l}\text { (i) Electric motor drives } \\
\text { (ii) Internal combustion engines }\end{array}$ & (i) Electric motor drives \\
\hline Characteristics and feature & $\begin{array}{l}\text { (i) Zero emission } \\
\text { (ii) Short driving range } \\
\text { (iii) Higher initial costs }\end{array}$ & $\begin{array}{l}\text { (i) Low emission } \\
\text { (ii) Longer range } \\
\text { (iii) Complex }\end{array}$ & $\begin{array}{l}\text { (i) Zero emission } \\
\text { (ii) Highest initial costs } \\
\text { (iii) Medium driving range }\end{array}$ \\
\hline Major techniques & $\begin{array}{l}\text { (i) Electric motor control } \\
\text { (ii) Battery management } \\
\text { (iii) Charging device }\end{array}$ & $\begin{array}{l}\text { (i) Electric motor control } \\
\text { (ii) Battery management } \\
\text { (iii) Managing multiple energy sources } \\
\text { and optimal system efficiency } \\
\text { (iv) Components sizing }\end{array}$ & $\begin{array}{l}\text { (i) Fuel processor } \\
\text { (ii) Fueling system } \\
\text { (iii) Fuel cell cost }\end{array}$ \\
\hline Regenerative braking & (i) Yes & (i) Yes & (i) Yes \\
\hline
\end{tabular}

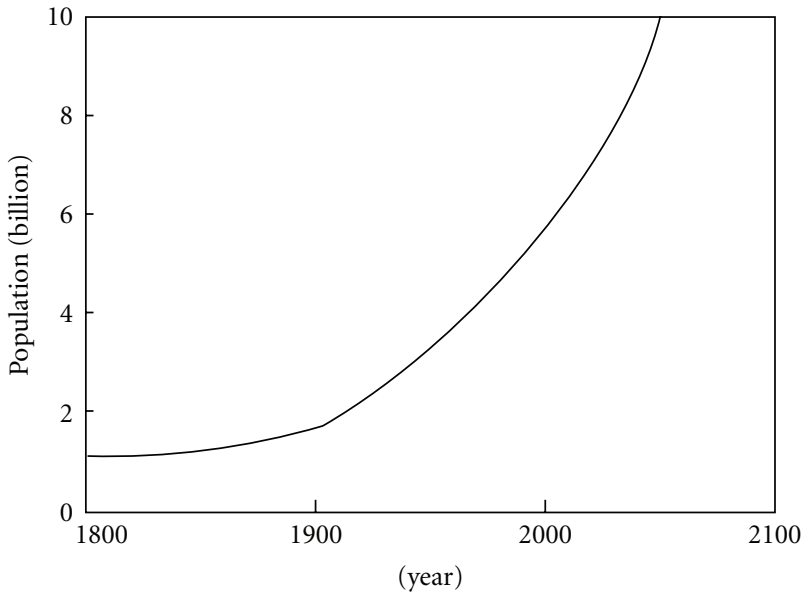

FIGURE 1: Growth of population.

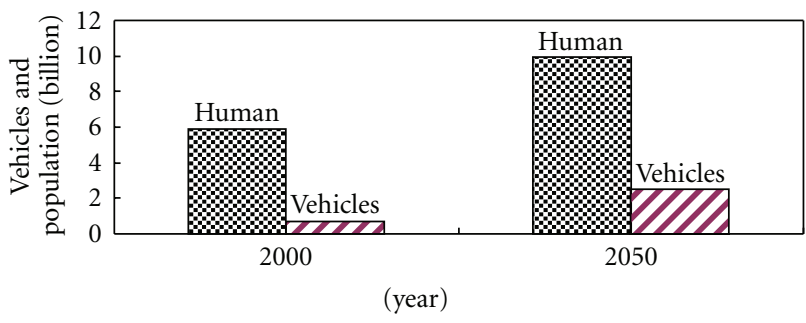

FIgURE 2: Vehicles and population.

\section{Configurations, Main Issues, and Control of HEV}

2.1. Configurations of HEVs. According to technical Committee 69 (electric road vehicles) of the International Electro technical Commission, an HEV is a vehicle in which propulsion energy is available from two or more kinds or types of energy sources or converters, and at least one of them can deliver electrical energy [1]. Based on this definition, there are many kinds of HEVs, for example, battery and ICE, battery and capacitor, and battery and flywheel. However, the above definition is not accepted by ordinary people. Generally, they think that HEV is a vehicle having electric motor and ICE, thus this general definition is adopted in this paper. Traditionally, HEV can be classified into three types: series HEV, parallel HEV, and combination $\mathrm{HEV}[11,12]$. Figure 3 shows the configurations of HEV, arrow represents the direction of the power flow.

2.1.1. Configuration of Series HEV. From Figure 3(a), we can see that the series HEV is composed of ICE, generator, power converter, motor, and battery. There is no mechanical connection between ICE and transmission, thus ICE can operate at maximum efficient point by regulating the output power of battery to satisfy the required power of vehicle. But, the energy from the ICE transmits via generator and motor, so much more energy will be lost. Since the motor is the final and sole drive device, the motor must be larger enough to satisfy performance of vehicle, and thus the regenerative braking power almost can be stored in battery by motor.

2.1.2. Configuration of Parallel HEV. From Figure 3(b), we can see that the parallel HEV allows both the electric motor and ICE to deliver power in parallel to drive the vehicle, that is, ICE and motor can drive, respectively, or together. Different from the series HEV, there is mechanical connection between ICE and transmission, and thus the ICE's rotational speed depends on the driving cycle, so the ICE can operate based on optimal operating line by regulating the output power of battery.

2.1.3. Configuration of Combination HEV. From Figure 3(c), we can see that the combination HEV incorporates the features of both series and parallel HEV, an additional mechanical connection between ICE and transmission is added compared with the series hybrid, and also an additional generator between ICE and power converter is added compared with the parallel hybrid. Although the complexity of structure leads to more costly manufacturing technologies, it is more flexible in control. Some modern HEVs prefer to adopt this system [13]; typical products of HEV are listed in Table 2. 


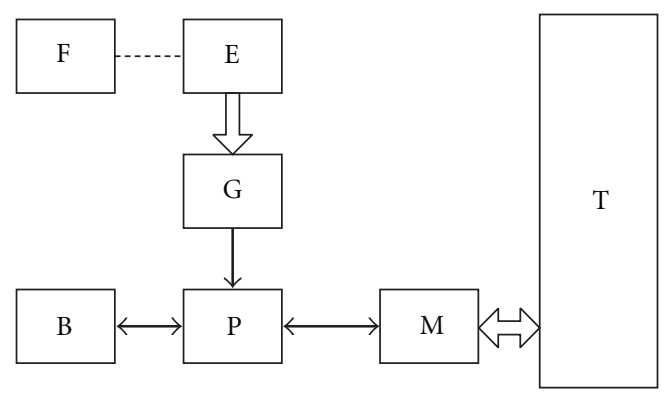

(a) Series HEV.

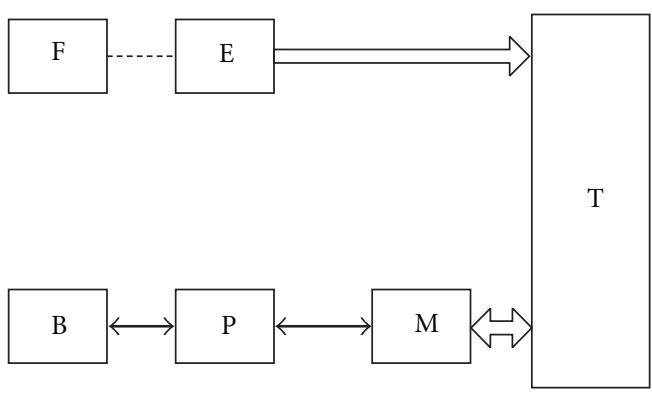

(b) Parallel HEV.

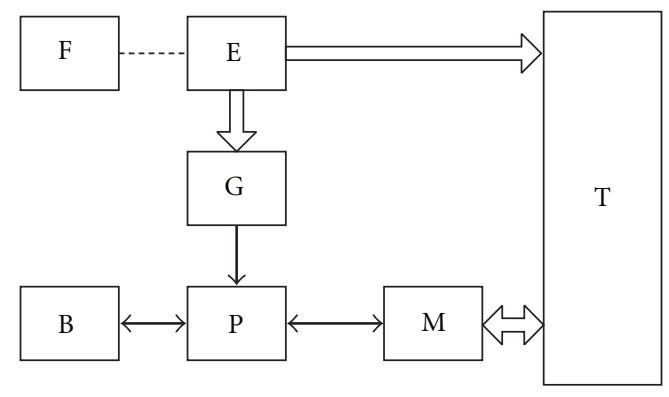

$\begin{array}{lll}\text { B: Battery } & \text { M: Motor } & -- \text { Hydraulic link } \\ \text { E: ICE } & \text { P: Power converter } & =\text { Mechanical link } \\ \text { F: Fuel tank } & \text { T: Transmission } & \text { Electrical link } \\ \text { G: Generator } & \end{array}$

(c) Combination HEV.

Figure 3: Power flow of HEV.

2.2. Main Issues of HEV. Compare to conventional vehicle, $\mathrm{HEV}$ can save fuel for the following reasons.

(i) HEV can store part of the vehicle's kinetic energy in battery while braking or downslope in which otherwise is burnt in the brake drums in the form of heat in conventional vehicle.

(ii) The ICE in an HEV can be designed with a smaller displacement without compromising the performance of vehicle [14].

(iii) HEV can make ICE operate at maximum efficiency point or optimal operating line by regulating the output power of battery to satisfy the required power of vehicle.

(iv) $\mathrm{HEV}$ is a multiple energy system; the main issue of $\mathrm{HEV}$ is how to optimize the power flow to obtain best fuel economy or low emission at lower cost, which is often referred to as the energy management (EM) problem. The issue will be discussed in next section in detail.

2.3. Control in HEV. The most critical aspect in designing $\mathrm{HEV}$ is to get most effective results with controlling conversion of energy on the powertrain. Therefore, the controller design of HEV is the key point of the design process. The aim of this section is to explain powertrain control strategies for
TABLE 2: Typical products of HEV.

\begin{tabular}{lccc}
\hline Products & Configuration & Automobile companies & Year \\
\hline Prius & Combination & Toyota & 1997 \\
Insight & Parallel & Honda & 1999 \\
Tino & Combination & Nissan & 2000 \\
Civic & Parallel & Honda & 2001 \\
Lexus LS 600h & Combination & Toyota & 2007 \\
Toyota Auris & Combination & Toyota & 2010 \\
Lexus CT 200h & Combination & Lexus & 2011 \\
\hline
\end{tabular}

HEV and review the latest methods of EM strategies in detail. The aim of the control strategies is to satisfy a number of goals for HEV [15-18]:

(i) Minimization of fuel consumption or maximum of fuel economy.

(ii) Minimization of emissions.

(iii) Good drivability.

2.3.1. Vehicle Control in HEV. HEV's control system is very complex. The multilevel hierarchical control is an important control method for large-scale and complex system $[19,20]$. Thus hierarchical control is adapted widely in HEV control as shown in Figure 4 (series HEV). HEV controller consists of 


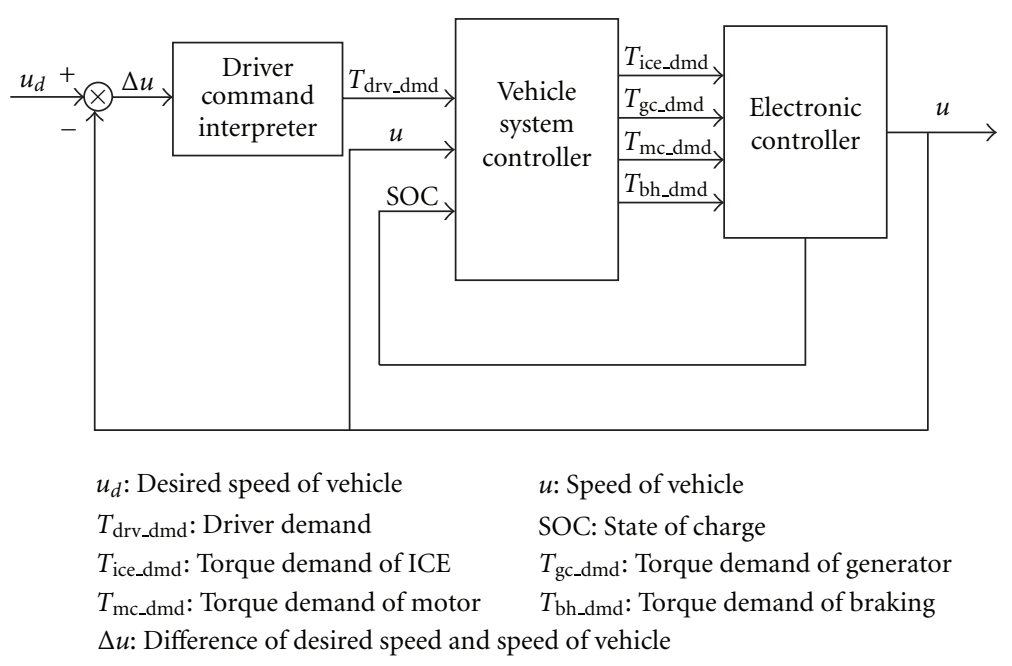

Figure 4: Block diagram of HEV controller.

driver command interpreter, vehicle system controller, and electronic controller. Vehicle system controller is the decision level to decide the torque demands of motor, generator, ICE, and mechanical brake according to the driver's torque demand, speed of vehicle, and battery's state of charge (SOC), where the SOC is estimated by battery management system (BMS), the speed of vehicle is feed by sensor. Electronic controller is execution level to carry out the command from the vehicle system controller to make corresponding parts work.

(1) Driver Command Interpreter. The function of driver command interpreter is to compute the driver's torque demand according to desired speed of vehicle and actual speed of vehicle. Speed of vehicle is controlled by accelerator pedal and brake pedal position. This is a feed control system by adjusting the accelerator pedal and brake pedal position to make the vehicle follow the desired vehicle speed.

(2) Vehicle System Controller. Compared to the conventional vehicles, HEV is a multiple energy source, then, how to split the required power among energy sources is called EM. Vehicle system controller performs powertrain control by using EM strategies according to command signals received from driver command interpreter and parameters information feedback from electronic controller. Vehicle system controller can be divided into three function blocks as shown in Figure 5.

(i) Required power of vehicle interpreter.

(ii) Energy management strategies.

(iii) Torque interpreter.

Required power of vehicle interpreter is a function block to convert the driver's torque demand to power demand. HEV is a multiple energy system, different from conventional vehicles which can only output power, battery not only can output power but also absorb power. For a required power, how to split the power required between two energy sources and mechanical brake in order to minimum the fuel consumption or emission is the hot topic among technology developers. In the next section, EM will be discussed. Then, torque interpreter converts the power demand of ICE and mechanical brake to torque demands of ICE, generator, motor, and mechanical brake.

(3) Electronic Controller. Electronic controller is the embedded system which carries out the commands from the vehicle system controller to make corresponding parts work. Electronic controller in Figure 4 includes engine control unit (ECU), motor control unit (MCU), generator control unit (GCU), electronic braking system control (mechanical brake) unit, and battery management system (BMS).

Engine control unit is an electronic control unit (ECU) for controlling ICE; it makes the ICE output desired torque coming from vehicle system controller command signal by injecting fuel into the combustion chambers of the ICE. ICE's operating point can be described by torque and speed. In series HEV, there is no mechanical connection between ICE and transmission, then how to control the speed of ICE? There is a mechanical connection between ICE and generator, so ICE's speed is controlled by generator's torque demand. Motor is the final drive device and coupled by mechanical connection to transmission, and so the motor's speed depends on the driving cycle, similarly, motor's operating point can be described by torque and speed usually; the torque demand of motor is computed by driver's torque demand due to mechanical connection to transmission. MCU makes the motor operate at desired torque using FOC echnology usually. Motors, used for traction usually, are also able to become generator during braking or down slope. Hence, the vehicle kinetic energy, which otherwise is burnt in the brake drums in the form of heat, can be converted into electrical energy and sent back to the battery. If the battery is unreceptive, then electronic braking system control unit can be work.

2.3.2. Energy Management for HEV. There have been a number of surveys on EM strategies for HEV. Early EM is designed based on rules for its effectiveness in real time supervisory control of power flow in a hybrid powertrain, which is 


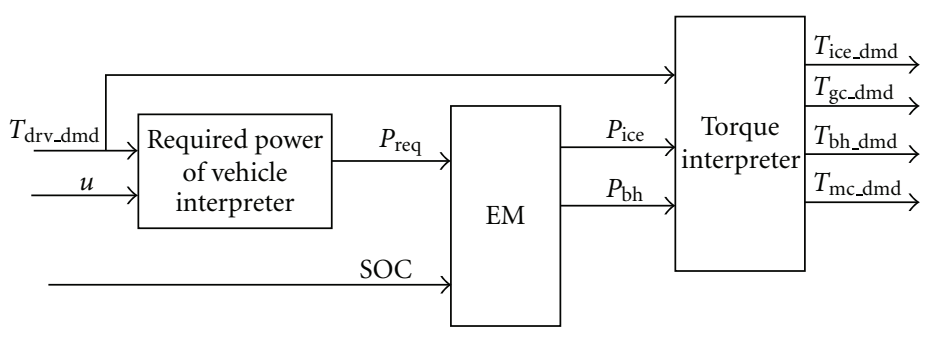

$P_{\text {req }}:$ Required power of vehicle $\quad P_{\text {ice }}$ : Output power command of ICE

$P_{\text {bh }}$ : Output power command of mechanical brake

FIGURE 5: Block diagram of vehicle system controller.

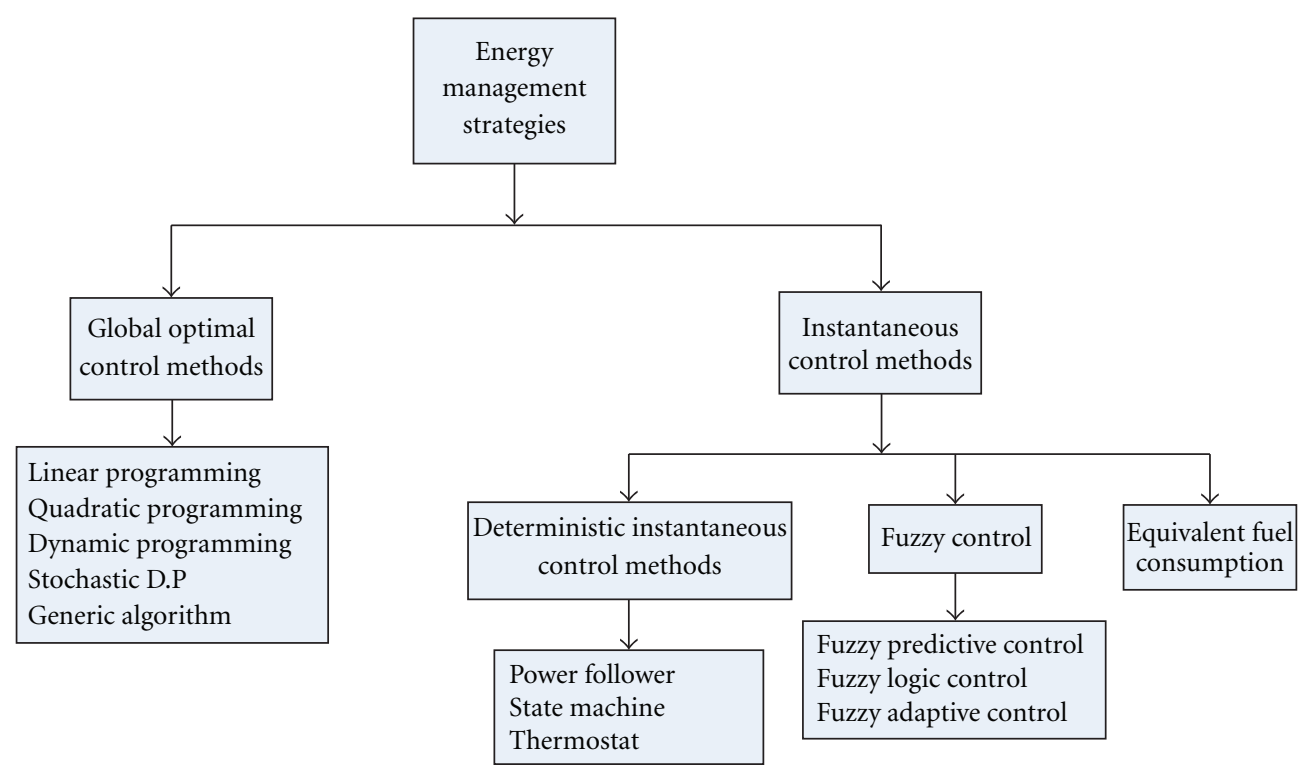

FIGURE 6: Energy management control strategies for HEV.

set up on the basis of heuristics, intuition, and human expertise. For example, the maximum torque ICE can produce is low at low speed, while the motor is high at low speeds. So, heuristics EM strategies are to make the vehicle run in purely electrical mode from standstill to a low vehicle speed. When the vehicle speeds up from this speed, the ICE will turn on and operate based on optimal operating line. Global optimal control methods are adapted subsequently. In a word, EM for HEV can be divided into two main methods as shown in Figure 6, Global optimal control methods, and instantaneous control methods.

(1) Global Optimal Control Methods. Some global optimal control methods based on optimal control theory have been developed recently. These methods aim at minimizing the energy loss or fuel consumption over a given period of time [21]. Due to use of the whole driving information in advance, the global optimum solutions can be found. Obviously, these approaches cannot be used in real time, but they might be basis of comparison for evaluating the quality of other EM strategies. Global optimal control methods used in EM strategies can be divided into the following methods: linear programming (LP) $[22,23]$, quadratic programming (QP), dynamic programming (DP) [24-27], stochastic dynamic programming (SDP) [28], and genetic algorithm (GA) [29].

Dynamic programming was founded to solve the shortest distance early. EM problem is similar with shortest distance problem, and so it is commonly solved by DP. DP requires gridding of SOC over a given driving cycle with a time discretization step $\Delta t$, and thus the optimal trajectory is calculated only for discretized point (SOC, $t$ ). But, the computational time increases linearly with the final driving cycle time. An approach, used to reduce the computing time is to split the driving cycle time into a series of time sections and solve an optimization problem for each of these sections. If the fuel consumption over the whole driving time is linearized, then the linear programming can be adopted to solve the optimization problem. Alternatively, if the fuel consumption over the whole driving cycle time is quadratic about variable, then quadratic programming can be used.

(2) Instantaneous Control Methods. Although global optimal control methods can obtain global optimum solution, it requires substantial amount of computational time and cannot 
be implemented real time. One method that often permits a reduction of computational time is the instantaneous control methods, and it only optimizes at instantaneous time. The greatest advantage of the methods is possible applied for real time. Instantaneous control methods can be divided into deterministic instantaneous methods, fuzzy control methods and equivalent fuel consumption method.

Deterministic instantaneous methods are designed via lookup tables to split the requested power between two energy sources. Deterministic instantaneous methods include power follower control, thermostat [30-36], and state machine [37]. Energy management problem for $\mathrm{HEV}$ is a multidisciplinary, time-varying, and nonlinear optimal problem; fuzzy logic control seems to be the most logical approach to the problem. The main advantages of fuzzy control methods are the following [38]: (1) robustness, since they are tolerant to imprecise measurements and component variations; (2) adaptation, since the fuzzy rules can be easily tuned, if necessary. Fuzzy control methods are divided into fuzzy logic control [39], fuzzy adaptive strategy [40], and fuzzy predictive strategy [40].

In equivalent fuel consumption method [41], in addition to an estimation for fuel consumption, variations of the stored electrical energy should be taken into account to guarantee electrical self-sustainability. Thus, variations of the electrical energy are added to cost function via penalty function. Since the fuel energy is not equal to electrical energy, so the equivalence factor is needed to convert the electrical energy to equivalent fuel energy. Then, the optimization problem is converted to evaluate the equivalence factor. All in all, Equivalence factor depends on the driving cycle. Telemetry ECM (T-ECM) [42] and adaptive ECM [41] are adopted to estimate the equivalence factor.

\section{Conclusion}

Environment protection and energy crisis have urged the development of EV. However, PEV is not widely used currently. The main reason is that they could not satisfy the consumers' need due to high initial cost and short driving range. Thus, BEV will be designed mainly for short range, such as community transportation. Although FCEV has longterm potential for future main stream vehicles due to zero emission and comparable driving range with conventional vehicles, the major challenge for developing FCEV is how to investigate low-cost FC and refueling system. Consequently, HEV can meet consumers' need currently and will grow in faster rate. The main issue of $\mathrm{HEV}$ is how to optimize the multiple energy sources to obtain best fuel economy or low emission at lower cost.

This paper has presented an overview of HEV with focus on the configurations, main issues, especially the control of $\mathrm{HEV}$, and it elaborates the EM approaches. The EM problem is the hot research area until now, and it is also the critical technology for HEV. Global optimization approach can obtain global optimum, but it requires substantial amount of computational time and does not implement real time, so the global optimization approach, such as DP, usually serves as a benchmark for evaluating other EM strategies. Instantaneous control methods only optimize at instantaneous time. So, the real-time application becomes possible.

\section{References}

[1] C. C. Chan, "The state of the art of electric and hybrid vehicles," Proceedings of the IEEE, vol. 90, no. 2, pp. 247-275, 2002.

[2] "Executive summary ES-1," http://www.epa.gov/climatechange/emissions/downloads09/GHG2007-ES-508.pdf.

[3] M. Rexeis and S. Hausberger, "Trend of vehicle emission levels until 2020-prognosis based on current vehicle measurements and future emission legislation," Atmospheric Environment, vol. 43, no. 31, pp. 4689-4698, 2009.

[4] C. C. Chan, "The state of the art of electric, hybrid, and fuel cell vehicles," Proceedings of the IEEE, vol. 95, no. 4, Article ID 4168013, pp. 704-718, 2007.

[5] C. C. Chan, A. Bouscayrol, and K. Chen, "Electric, hybrid, and fuel-cell vehicles: architectures and modeling," IEEE Transactions on Vehicular Technology, vol. 59, no. 2, Article ID 5276874, pp. 589-598, 2010.

[6] C. C. Chan and Y. S. Wong, "Electric vehicles charge forward," IEEE Power and Energy Magazine, vol. 2, no. 6, pp. 24-33, 2004.

[7] S. Campanari, G. Manzolini, and F. Garcia de la Iglesia, "Energy analysis of electric vehicles using batteries or fuel cells through well-to-wheel driving cycle simulations," Journal of Power Sources, vol. 186, no. 2, pp. 464-477, 2009.

[8] C. E. Sandy Thomas, "Transportation options in a carbonconstrained world: hybrids, plug-in hybrids, biofuels, fuel cell electric vehicles, and battery electric vehicles," International Journal of Hydrogen Energy, vol. 34, no. 23, pp. 9279-9296, 2009.

[9] S. Eaves and J. Eaves, "A cost comparison of fuel-cell and battery electric vehicles," Journal of Power Sources, vol. 130, no. 1-2, pp. 208-212, 2004.

[10] G. J. Offer, D. Howey, M. Contestabile, R. Clague, and N. P. Brandon, "Comparative analysis of battery electric, hydrogen fuel cell and hybrid vehicles in a future sustainable road transport system," Energy Policy, vol. 38, no. 1, pp. 24-29, 2010.

[11] E. W. C. Lo, "Review on the configurations of hybrid electric vehicles," in Proceedings of the $3 r$ International Conference on Power Electronics Systems and Applications (PESA '09), pp. 1-4, May 2009.

[12] K. Çağatay Bayindir, M. A. Gözüküçük, and A. Teke, "A comprehensive overview of hybrid electric vehicle: powertrain configurations, powertrain control techniques and electronic control units," Energy Conversion and Management, vol. 52, no. 2, pp. 1305-1313, 2011.

[13] A. Emadi, K. Rajashekara, S. S. Williamson, and S. M. Lukic, "Topological overview of hybrid electric and fuel cell vehicular power system architectures and configurations," IEEE Transactions on Vehicular Technology, vol. 54, no. 3, pp. 763-770, 2005.

[14] A. Sciarretta and L. Guzzella, "Control of hybrid electric vehicles," IEEE Control Systems Magazine, vol. 27, no. 2, pp. 60-70, 2007.

[15] P. Pisu and G. Rizzoni, "A comparative study of supervisory control strategies for hybrid electric vehicles," IEEE Transactions on Control Systems Technology, vol. 15, no. 3, pp. 506$518,2007$.

[16] O. D. Momoh and M. O. Omoigui, "An overview of hybrid electric vehicle technology," in Proceedings of the 5th IEEE Vehicle Power and Propulsion Conference (VPPC '09), pp. 1286-1292, September 2009. 
[17] G. J. Offer, D. Howey, M. Contestabile, R. Clague, and N. P. Brandon, "Comparative analysis of battery electric, hydrogen fuel cell and hybrid vehicles in a future sustainable road transport system," Energy Policy, vol. 38, no. 1, pp. 24-29, 2010.

[18] G. E. Katsargyri, I. V. Kolmanovsky, J. Michelini et al., "Optimally controlling hybrid electric vehicles using path forecasting," in Proceedings of the American Control Conference (ACC '09), pp. 4613-4617, June 2009.

[19] S. Li, Fuzzy Control. Neurocontrol and Intelligent Cybernetics, Haerbin University of Technology, Heilongjiang, China, 1998.

[20] M. Huang, "Optimal multilevel hierarchical control strategy for parallel hybrid electric vehicle," in Proceedings of the Vehicle Power and Propulsion Conference, pp. 1-4, 2006.

[21] D. Karbowski and A. Rousseau, "Plug-in vehicle control strategy: from global optimization to real time application," in Proceedings of the 22th International Electric Vehicle Symposium, S. Pagerit and P. Sharer, Eds., 2006.

[22] E. D. Tate and S. P. Boyd, "Finding ultimate limits of performance for hybrid electric vehicles," Tech. Rep. SAE 2000-013099, 2000.

[23] L. V. Pérez and E. A. Pilotta, "Optimal power split in a hybrid electric vehicle using direct transcription of an optimal control problem," Mathematics and Computers in Simulation, vol. 79, no. 6, pp. 1959-1970, 2009.

[24] C. C. Lin, H. Peng, J. W. Grizzle, and J. M. Kang, "Power management strategy for a parallel hybrid electric truck," IEEE Transactions on Control Systems Technology, vol. 11, no. 6, pp. 839-849, 2003.

[25] L. V. Pérez, G. R. Bossio, D. Moitre, and G. O. García, "Optimization of power management in an hybrid electric vehicle using dynamic programming," Mathematics and Computers in Simulation, vol. 73, no. 1-4, pp. 244-254, 2006.

[26] L. V. Perez, G. R. Bossio, D. Moitre, and G. O. Garcia, "Supervisory control of an HEV using an inventory control approach," Latin American Applied Research, vol. 36, no. 2, pp. 93$100,2006$.

[27] A. Brahma, Y. Guezennec, and G. Rizzoni, "Optimal energy management in series hybrid electric vehicles," in Proceedings of the American Control Conference, pp. 60-64, Chicago, Ill, USA, June 2000.

[28] C. C. Lin, H. Peng, and J. W. Grizzle, "A stochastic control strategy for hybrid electric vehicles," in Proceedings of the American Control Conference (AAC '04), pp. 4710-4715, Boston, Mass, USA, July 2004.

[29] A. Piccolo, L. Ippolito, V. Zo Galdi, and A. Vaccaro, "Optimisation of energy flow management in hybrid electric vehicles via genetic algorithms," in Proceedings of the IEEE/ASME International Conference on Advanced Intelligent Mechatronics, pp. 434-439, July 2001.

[30] C. Anderson and E. Pettit, "The effects of APU characteristics on the design of hybrid control strategies for hybrid electric vehicles,” Tech. Rep. SAE 950493, 1995.

[31] C. Hochgrat, M. Ryan, and H. Wiegman, "Engine control strategy for a series hybrid electric vehicle incorporating load-leveling and computer controlled energy management," Tech. Rep. SAE 960230, 1996.

[32] S. Barsali, M. Ceraolo, and A. Possenti, "Techniques to control the electricity generation in a series hybrid electrical vehicle," IEEE Transactions on Energy Conversion, vol. 17, no. 2, pp. 260-266, 2002.

[33] H. Ed Bargar, J. Li, D. J. Goering, and J. H. Lee, "Modeling and verification of hybrid electric HMMWV performance," in Proceedings of the 29th Annual Conference of the IEEE Industrial Electronics Society, pp. 939-944, November 2003.
[34] S. Aoyagi, Y. Hasegawa, T. Yonekura, and H. Abe, "Energy efficiency improvement of series hybrid vehicle," JSAE Review, vol. 22, no. 3, pp. 259-264, 2001.

[35] N. Sadegh, B. Khan, and J. Meisel, "Optimization of the fuel consumption of a parallel hybrid electric vehicle," in Proceedings of the IEEE/ASME International Conference on Advanced Intelligent Mechatronics (AIM '05), pp. 128-133, July 2005.

[36] J. P. Gao, G. M. G. Zhu, E. G. Strangas, and F. C. Sun, "Equivalent fuel consumption optimal control of a series hybrid electric vehicle," Proceedings of the Institution of Mechanical Engineers, Part D: Journal of Automobile Engineering, vol. 223, no. 8, pp. 1003-1018, 2009.

[37] A. M. Phillips, M. Jankovic, and K. E. Bailey, "Vehicle system controller design for a hybrid electric vehicle," in Proceedings of the IEEE International Conference on Control Applications, pp. 297-302, 2000.

[38] F. R. Salmasi, "Control strategies for hybrid electric vehicles: evolution, classification, comparison, and future trends," IEEE Transactions on Vehicular Technology, vol. 56, no. 5, part 1, pp. 2393-2404, 2007.

[39] H. D. Lee and S. K. Sul, "Fuzzy-logic-based torque control strategy for parallel-type hybrid electric vehicle," IEEE Transactions on Industrial Electronics, vol. 45, no. 4, pp. 625-632, 1998.

[40] G. Rajagopalan, G. Washington, G. Rizzoni, and Y. Guezennec, "Development of fuzzy logic control and advanced emissions modeling for parallel hybrid vehicles," NREL Report SR-54032919, 2003.

[41] C. Musardo, G. Rizzoni, and B. Staccia, "A-ECMS: an adaptive algorithm for hybrid electric vehicle energy management," in Proceedings of the 44th IEEE Conference on Decision and Control, and the European Control Conference (CDC-ECC '05), pp. 1816-1823, December 2005.

[42] A. Sciarretta, L. Guzzella, and M. Back, "A real-time optimal control strategy for parallel hybrid vehicles with on-board estimation of control parameters," in Proceedings of the IFAC Symposium Advances in Automotive Control, vol. 136, pp. 502-507, Salerno, Italy, 2004. 

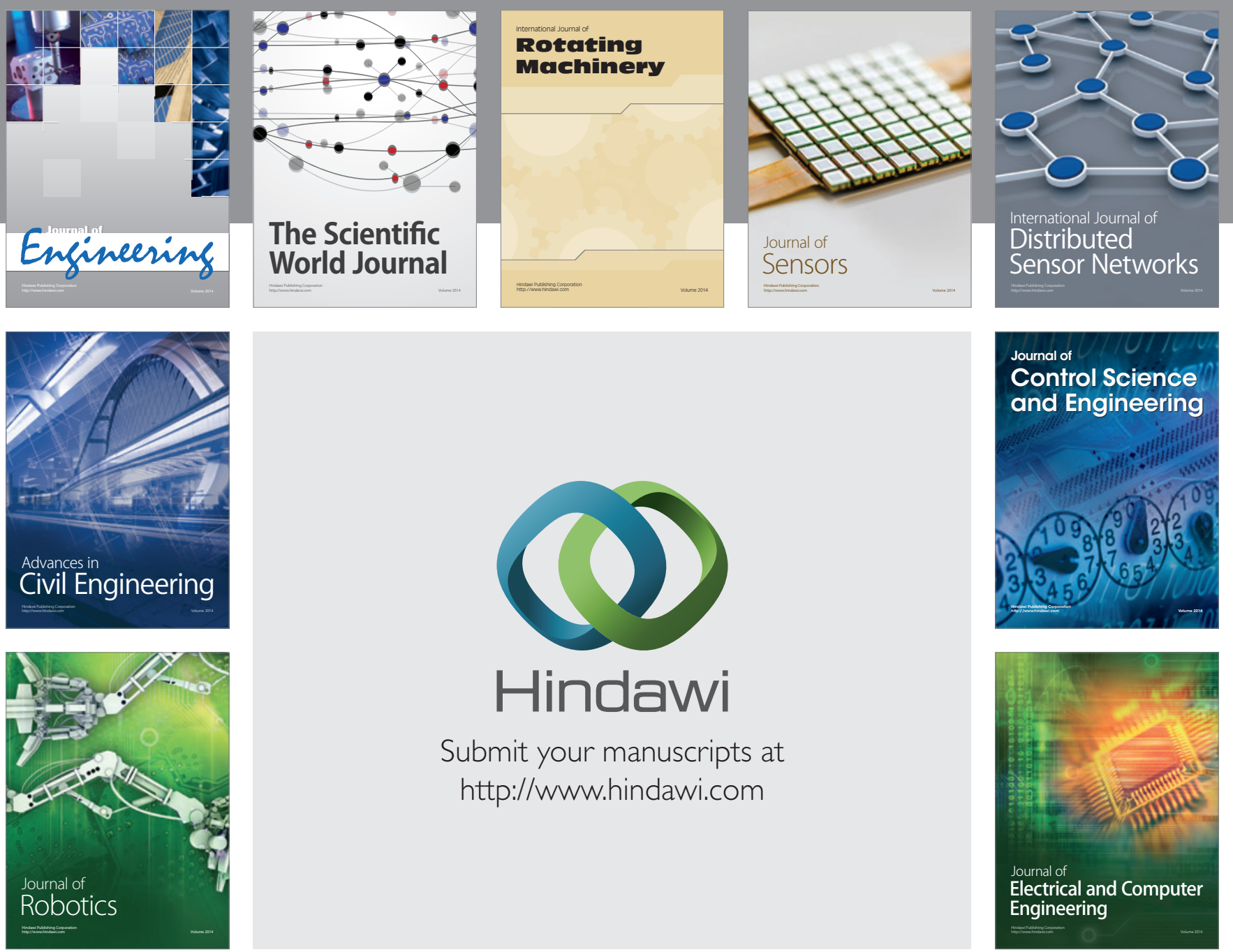

Submit your manuscripts at

http://www.hindawi.com
